\title{
Electrochemical Actuation of Growing Copper
}

\section{Dendrimers in Water}

${ }^{1}$ Biswa Ranjan Panda, ${ }^{2}$ Pinjala Nagaraju Rao, ${ }^{1}$ Anumita Paul* $\&{ }^{1,3}$ Arun Chattopadhyay*

${ }^{1}$ Department of Chemistry, ${ }^{2}$ Department of Chemical Engineering and ${ }^{3}$ Centre for Nanotechnology, Indian Institute of Technology Guwahati, Guwahati 781 039, India

Email: anumita@iitg.ernet.in; arun@iitg.ernet.in

SUPPLEMENTARY INFORMATION - I

PART A

Table SI-1. Cells and electrolytes used along with the compositions of the resulting dendritic structures (the slash sign means or)

\begin{tabular}{|c|c|c|c|}
\hline $\begin{array}{c}\text { Cathode } \\
\text { (made of single metal) }\end{array}$ & Electrolyte & Anode & $\begin{array}{l}\text { Composition of the } \\
\text { Dendritic structure }\end{array}$ \\
\hline $\mathrm{Ag} / \mathrm{Al} / \mathrm{Au} /$ Stainless Steel & Dilute $\mathrm{HCl}$ & $\mathrm{Cu}$ & Only $\mathrm{Cu}$ \\
\hline $\mathrm{Ag} / \mathrm{Al} / \mathrm{Au} /$ Stainless Steel & $\mathrm{HAuCl}_{4}$ in dil. $\mathrm{HCl}$ & $\mathrm{Cu}$ & $\mathrm{Au}$ and $\mathrm{Cu}$ composite \\
\hline $\mathrm{Ag} / \mathrm{Al} / \mathrm{Au} /$ Stainless Steel & Aqueous $\mathrm{CuSO}_{4}$ & $\mathrm{Cu}$ & Only $\mathrm{Cu}$ \\
\hline $\mathrm{Ag} / \mathrm{Al} / \mathrm{Au} /$ Stainless Steel & Aqueous $\mathrm{CuCl}_{2}$ & $\mathrm{Cu}$ & Only $\mathrm{Cu}$ \\
\hline $\mathrm{Ag} / \mathrm{Al} / \mathrm{Au} /$ Stainless Steel & Aqueous $\mathrm{CdCl}_{2}$ & $\mathrm{Cu}$ & $\mathrm{Cd}$ and $\mathrm{Cu}$ composite \\
\hline $\mathrm{Ag} / \mathrm{Al} / \mathrm{Au} /$ Stainless Steel & Aqueous $\mathrm{CoCl}_{2}$ & $\mathrm{Cu}$ & $\mathrm{Co}$ and $\mathrm{Cu}$ composite \\
\hline $\mathrm{Ag} / \mathrm{Al} / \mathrm{Au} /$ Stainless Steel & Aqueous $\mathrm{AgNO}_{3}$ & $\mathrm{Cu}$ & $\mathrm{Ag}$ and $\mathrm{Cu}$ composite \\
\hline $\mathrm{Ag} / \mathrm{Al} / \mathrm{Au} /$ Stainless Steel & Aqueous $\mathrm{ZnCl}_{2}$ & $\mathrm{Cu}$ & $\mathrm{Zn}$ and $\mathrm{Cu}$ composite \\
\hline $\mathrm{Ag} / \mathrm{Al} / \mathrm{Au} /$ Stainless Steel & Aqueous $\mathrm{NiCl}_{2}$ & $\mathrm{Cu}$ & $\mathrm{Ni}$ and $\mathrm{Cu}$ composite \\
\hline $\mathrm{Ag} / \mathrm{Al} / \mathrm{Au} /$ Stainless Steel & Aqueous $\mathrm{Pb}\left(\mathrm{NO}_{3}\right)_{2}$ & $\mathrm{Cu}$ & $\mathrm{Pb}$ and $\mathrm{Cu}$ composite \\
\hline $\mathrm{Ag} / \mathrm{Al} / \mathrm{Au} /$ Stainless Steel & Water (milli-Q) & $\mathrm{Cu}$ & Only $\mathrm{Cu}$ \\
\hline
\end{tabular}




\section{Observations}

\section{Energy Dispersive X-ray (EDX) Analysis of Bimetallic Fibers}

The fibers were grown on a glass slide at the cathode to observe EDX spectrum using a LEO scanning electron microscope (model $1430 \mathrm{VP}$ ). The measurements were made at an applied voltage of $20 \mathrm{KV}$. A typical EDX analysis of fibers grown in the presence of $10^{-4} \mathrm{M} \mathrm{CoCl}_{2}$ at 12 $\mathrm{V}$ is given below. The EDX analysis clearly demonstrates the graded composition in a grown fiber.

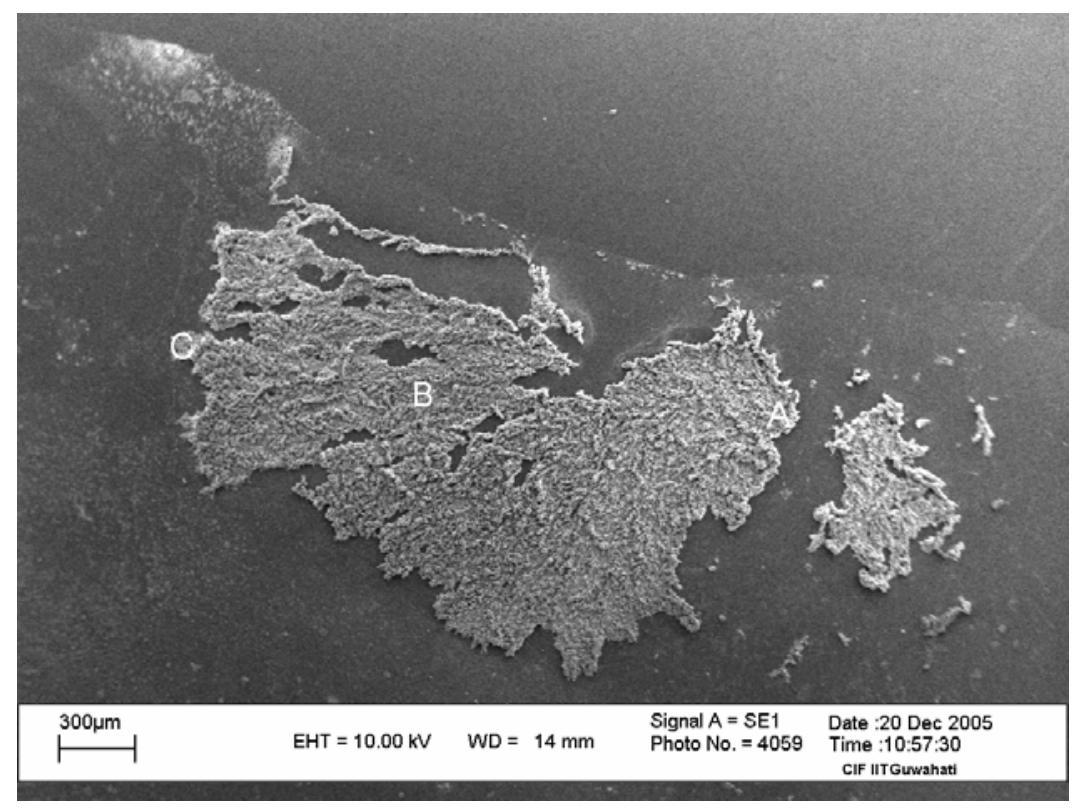

Figure S1a: Growth of bimetallic nanostructured dendrites (A - location close to the cathode, $\mathrm{B}$ - intermediate location, $\mathrm{C}$ - location far away from the cathode) 


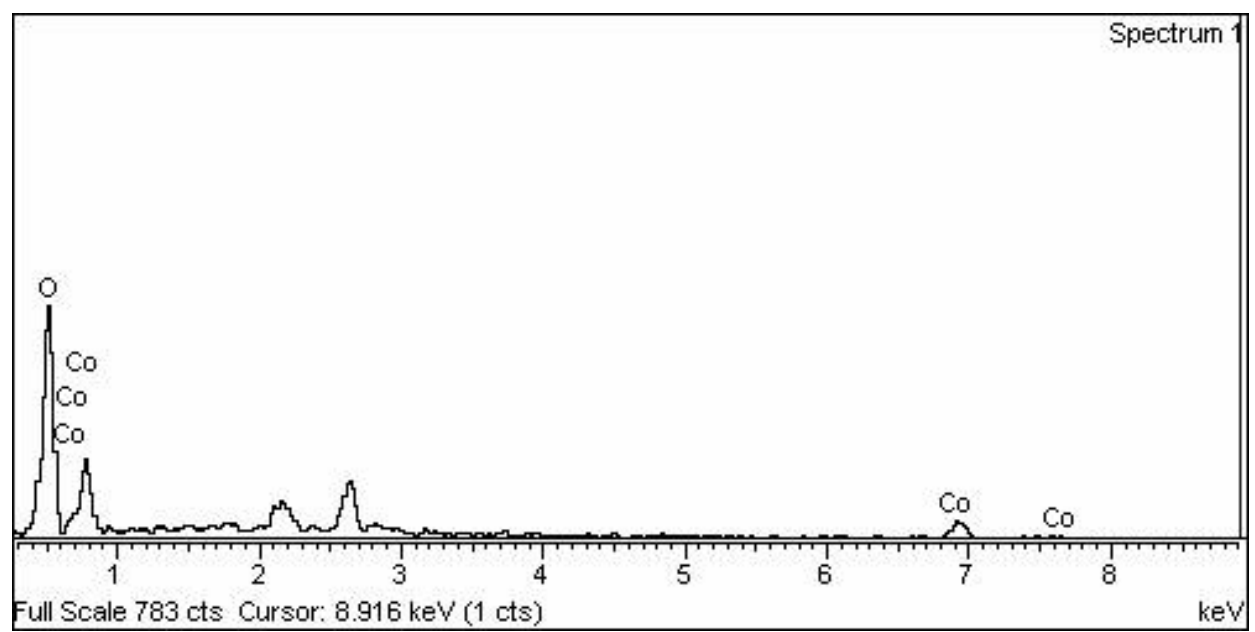

Figure S1b: EDX spectrum at location - A, close to the cathode

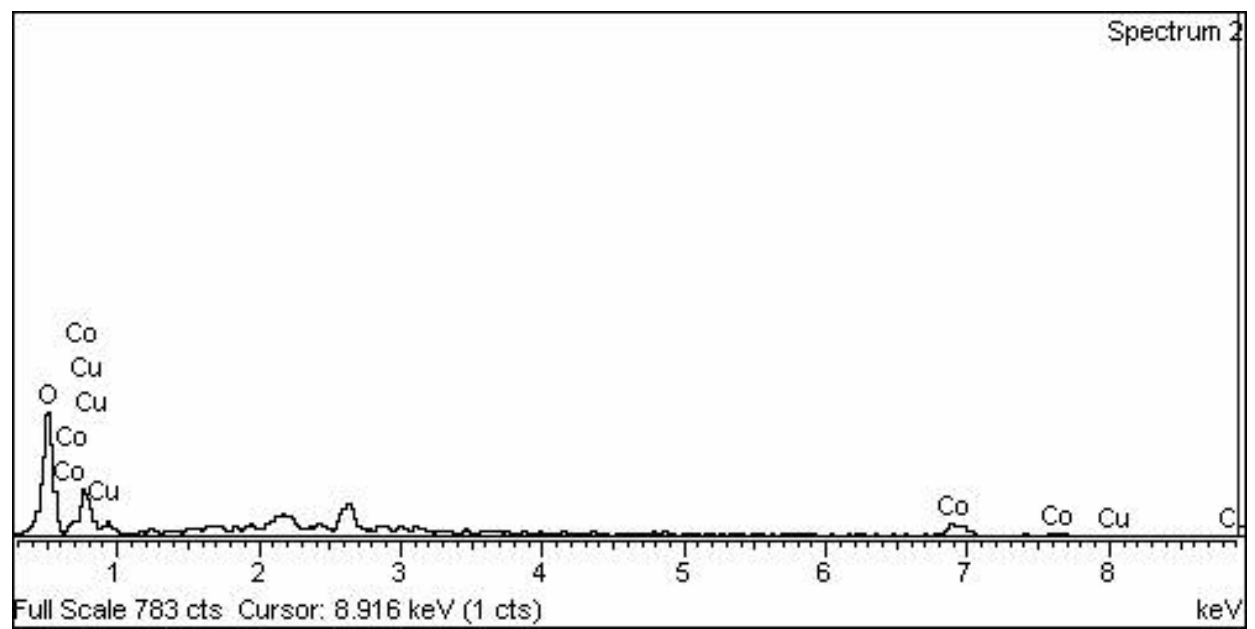

Figure S1c: EDX spectrum at location - B, any intermediate point between the anode and cathode

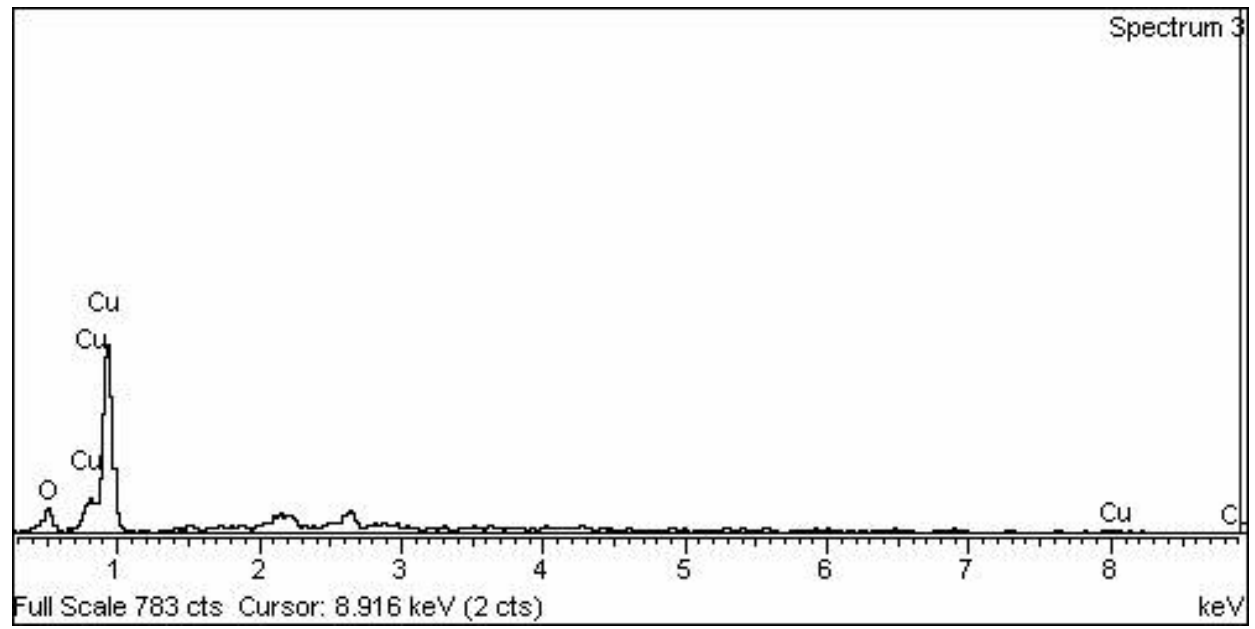

Figure S1d: EDX at location - C, far away from the cathode 
Also, a typical EDX analysis of fibers grown in the presence of $10^{-4} \mathrm{M} \mathrm{ZnCl}_{2}$ at $6 \mathrm{~V}$ is shown below.

A
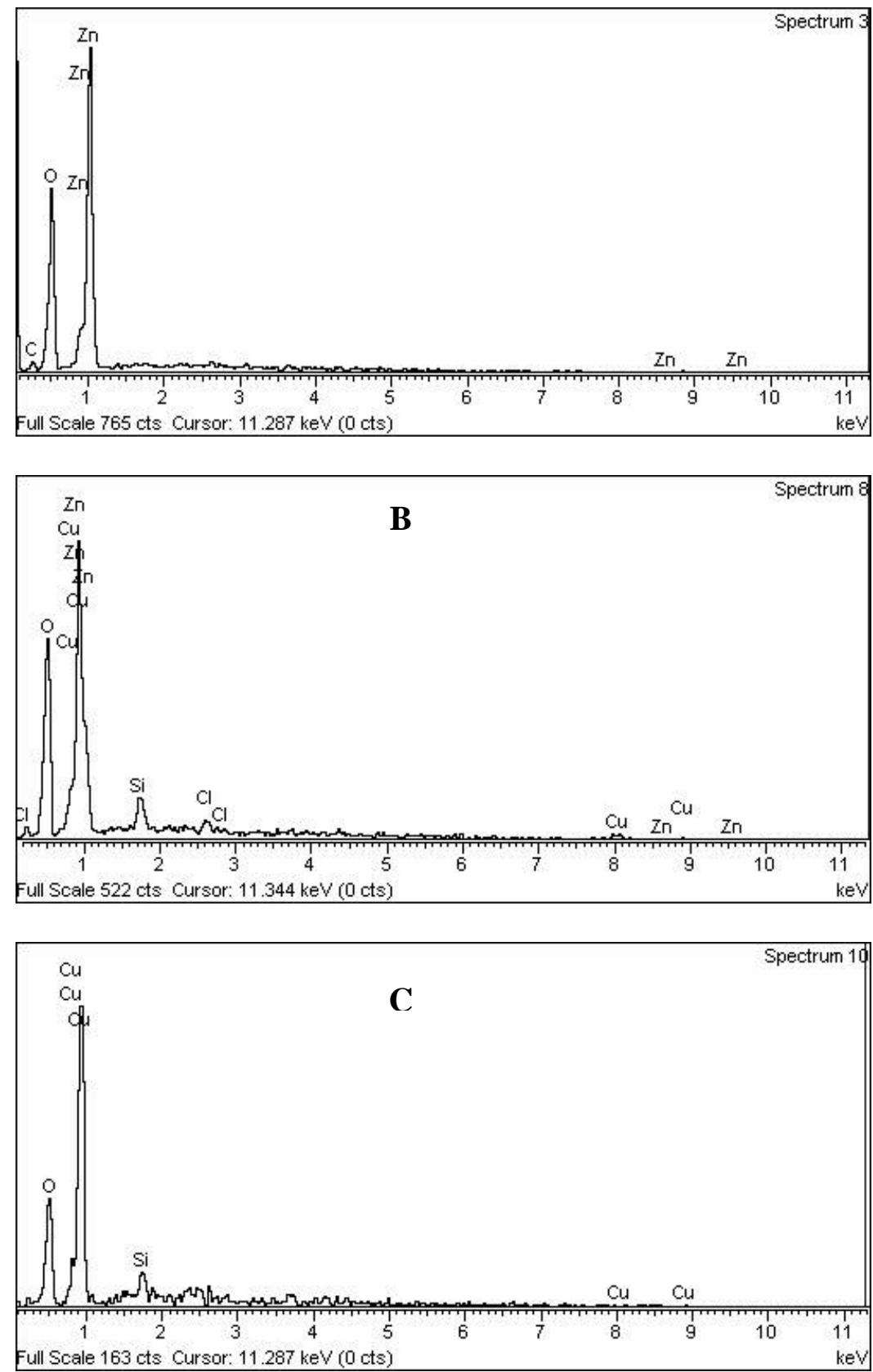

Figure S2: EDX spectrum of a dendritic fibrous structure near the origin (A) i.e. the cathode surface, at an intermediate spot (B) and near termination (C) of a growth when aq. $\mathrm{ZnCl}_{2}\left(10^{-4} \mathrm{M}\right)$ was used as the electrolyte. The fibers were grown at $6 \mathrm{~V}$. The background Si signal is due to the glass substrate. 


\section{Scanning Electron Microscopy}

Typical scanning electron microscopic images of the fiber ( $\mathrm{Co}-\mathrm{Cu}$ bimetallic) are shown below. These images that the dendritic structures are composed of nanoscale components of few $100 \mathrm{~nm}$ diameters.

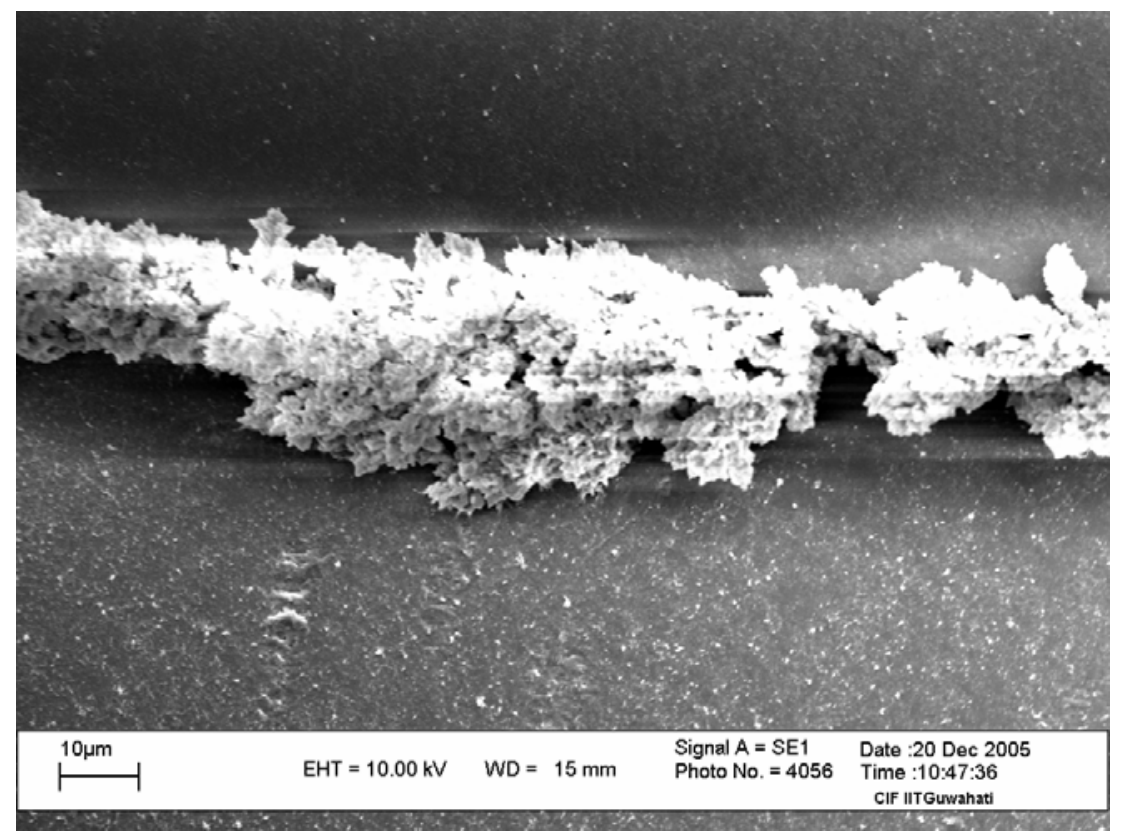

Figure S3a: Single dendritic nanofiber

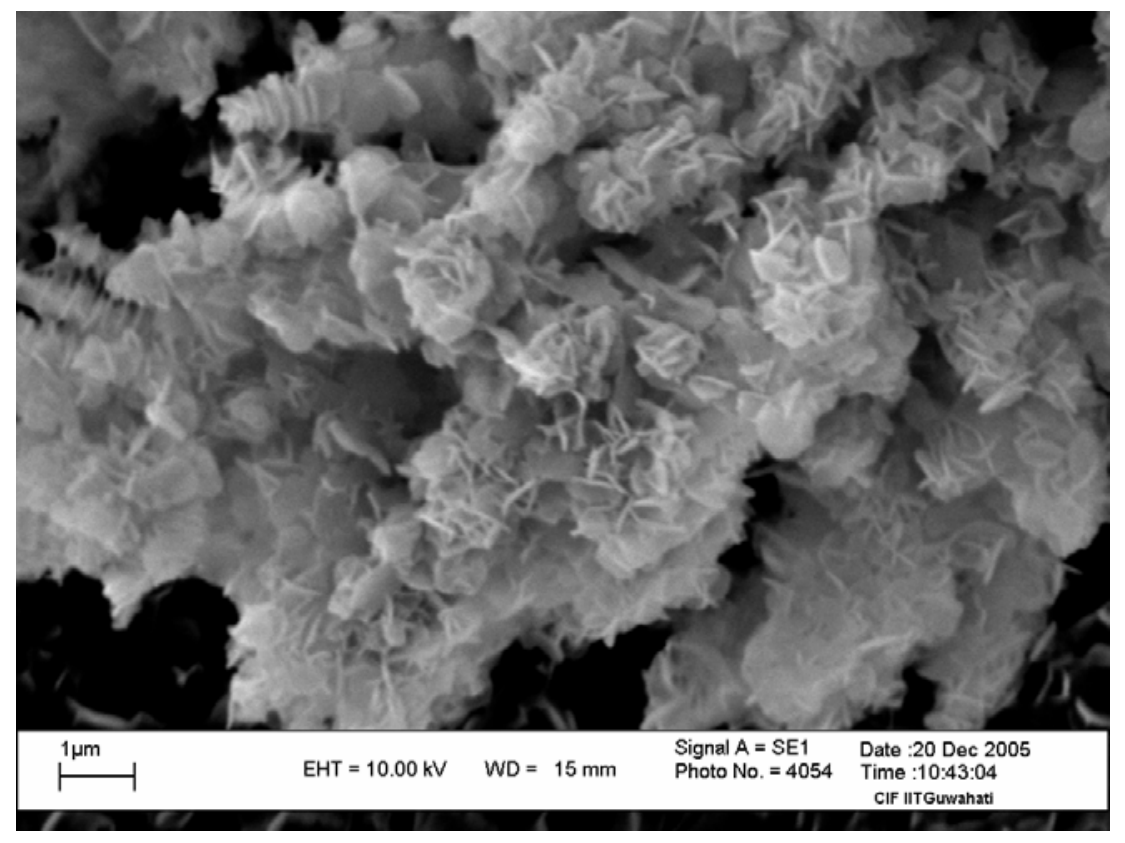

Figure S3b: Nanoscopic components in the dendritic nanofiber 


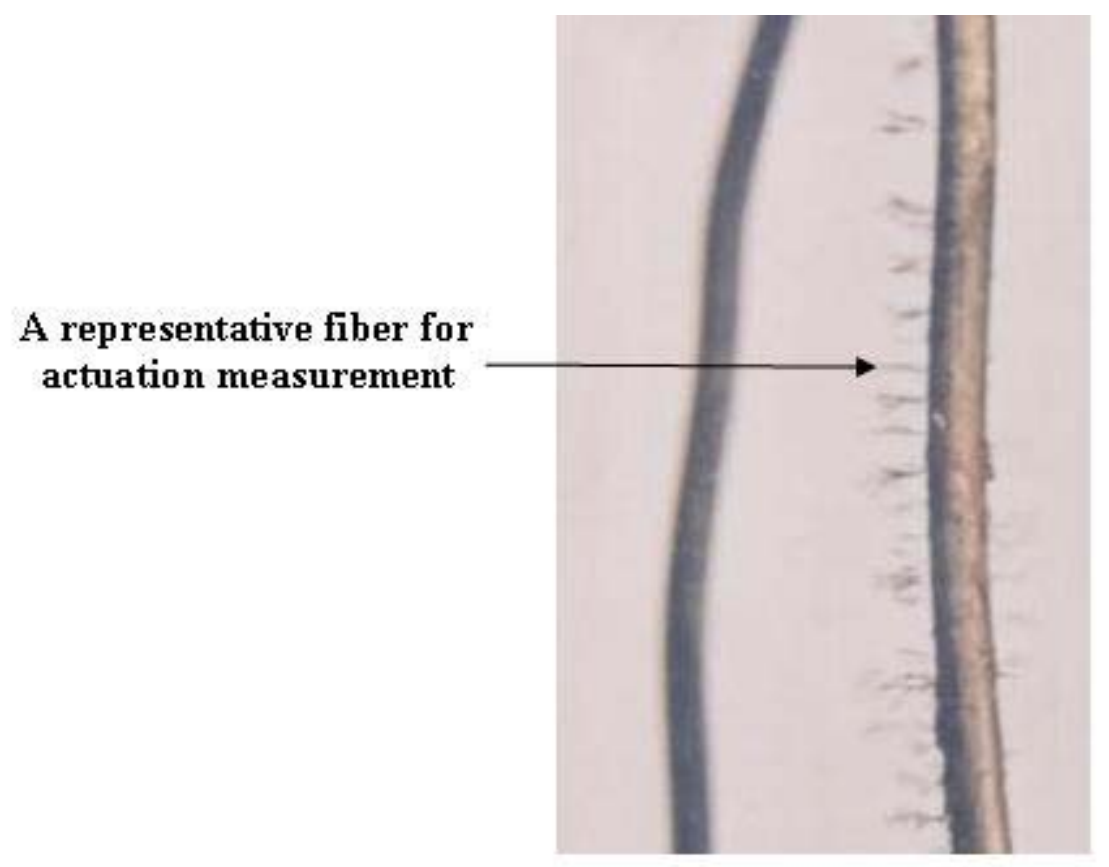

Figure S4: A representative fiber on cathode (marked by an arrow) used for actuation measurements.

\section{PART B}

\section{Validation of Lippmann Equation}

The angle of actuation is dependent on the applied voltage, characteristic dimensions of the growing fiber and many other assumptions as mentioned in the main manuscript. The experimental results presented in Figure 4 of the manuscript are consistent with electrocapillary forces governed by Lippman equation as shown below.

The change in interfacial tension across electrified interface of the fibre is given by Lippman equation as,

$$
\begin{gathered}
\Delta \gamma=-\left(\frac{\varepsilon}{8 \pi d} V^{2}\right) \\
\Delta \gamma=\gamma-\gamma_{\max }
\end{gathered}
$$

The relation between interfacial tension $(\gamma)$ and contact angle $(\theta)$ for the electrified interface formed by the fiber and the surrounding fluid layer is

$$
\gamma=\frac{r h g \Delta \rho}{2 \cos \theta}
$$


From above equations, $\gamma$ is inversely proportional to $\cos \theta$ within limits of small actuation angle. Also, $\gamma$ is proportional to $\mathrm{V}^{2}$. Hence, $1 / \cos \theta$ should vary linearly with $\mathrm{V}^{2}$.

From the data given in Figure 4 of the main manuscript we have,

Table S2 and Figure S5.

\begin{tabular}{|c|c|c|c|}
\hline Applied Voltage (V) & $\begin{array}{c}\text { Angle of actuation } \\
(\boldsymbol{\theta}) \text { radians }\end{array}$ & $\cos \boldsymbol{1}$ & $\mathbf{1} \cos \boldsymbol{\theta}$ \\
\hline 1.5 & 0.24 & 0.97 & 1.03 \\
\hline 3 & 0.51 & 0.87 & 1.14 \\
\hline 4.5 & 0.98 & 0.56 & 1.79 \\
\hline 6 & 1.15 & 0.41 & 2.46 \\
\hline 7.5 & 1.31 & 0.26 & 3.87 \\
\hline
\end{tabular}

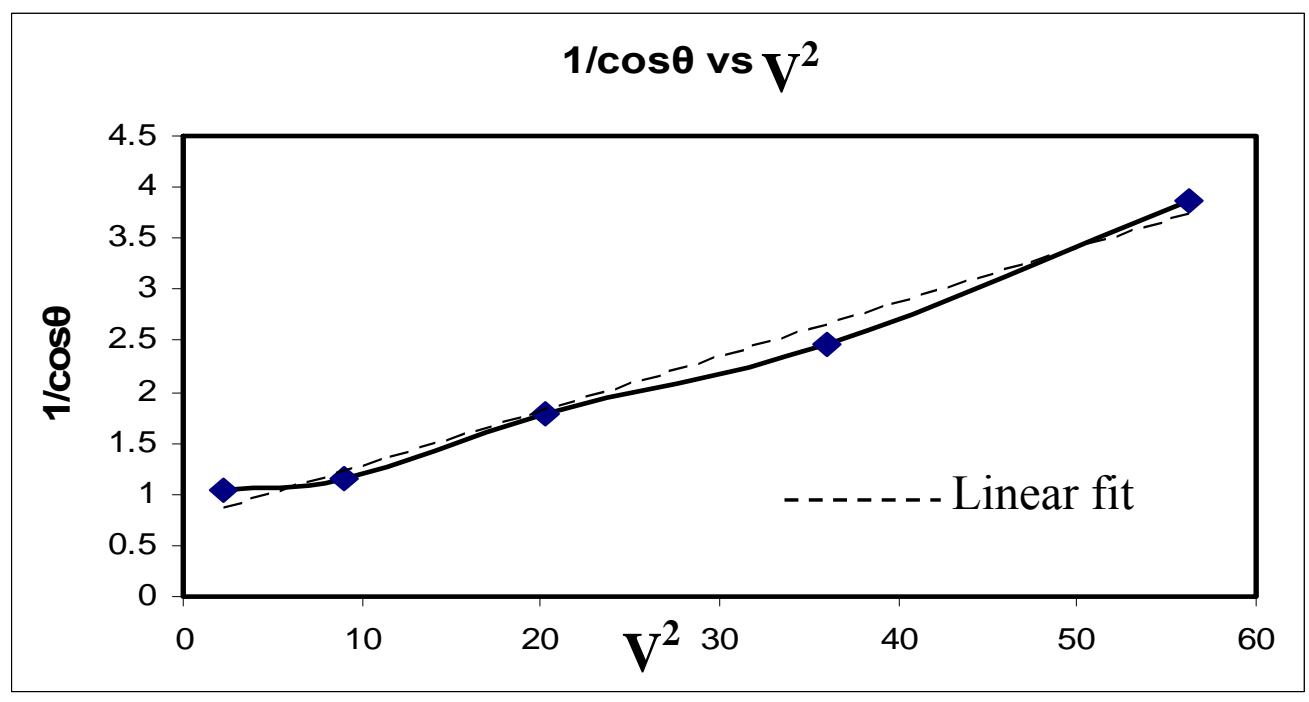

The above plot (Figure S5) demonstrates that $1 / \cos \theta$ varies linearly with $\mathrm{V}^{2}$ and hence consistent with Lippman equation within limits of small actuation angle. 